\title{
Influence of Annealing on Magnesioferrite Nanoparticles Synthesized by a Sol-Gel/Combustion Method
}

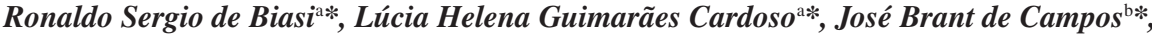 \\ Dalber Ruben Sanchez ${ }^{\mathrm{c} *}$, João Batista Marimon da Cunha ${ }^{\mathrm{d} *}$ \\ ${ }^{a}$ Seção de Engenharia Mecânica e de Materiais, Instituto Militar de Engenharia, \\ Pr. Gen. Tibúrcio, 80, SE/4, Urca, 22290-270 Rio de Janeiro - RJ, Brazil \\ ${ }^{\mathrm{b}}$ Divisão de Processamento e Caracterização de Materiais, Instituto Nacional de Tecnologia, \\ Av. Venezuela, 82, Saúde, 20081-312 Rio de Janeiro - RJ, Brazil \\ 'Instituto de Física, Universidade do Estado do Rio de Janeiro, \\ R. São Francisco Xavier, 524, Maracanã, 20550-013 Rio de Janeiro - RJ, Brazil \\ ${ }^{\mathrm{d} I n s t i t u t o}$ de Física, Universidade Federal do Rio Grande do Sul, \\ Av. Bento Gonçalves 9500, 91501-970 Porto Alegre - RS, Brazil
}

Received: September 18, 2008; Revised: April 2, 2009

\begin{abstract}
Nanocrystalline particles of magnesioferrite $\left(\mathrm{MgFe}_{2} \mathrm{O}_{4}\right)$ were prepared by a sol-gel/combustion method using iron nitrate, $\mathrm{Fe}\left(\mathrm{NO}_{3}\right)_{3} \cdot 9 \mathrm{H}_{2} \mathrm{O}$, magnesium nitrate, $\mathrm{Mg}\left(\mathrm{NO}_{3}\right)_{2} \cdot 6 \mathrm{H}_{2} \mathrm{O}$, and citric acid, $\mathrm{C}_{6} \mathrm{H}_{8} \mathrm{O}_{7} \cdot \mathrm{H}_{2} \mathrm{O}$, and annealed for 2 hours at 400,500 and $600{ }^{\circ} \mathrm{C}$. The average particle size, determined by $\mathrm{X}$ ray diffraction, was found to depend on the annealing temperature and varied from $\langle\mathrm{D}\rangle=8.1$ to $\langle\mathrm{D}\rangle=17.8 \mathrm{~nm}$. By measuring at several temperatures the relative intensity of the Mössbauer spectra due to superparamagnetic particles and to ferrimagnetic particles, we determined the size distribution of the nanoparticles in the samples. It was found to be a log-normal distribution with a most probable diameter that varied from $\mathrm{Dm}=6.4$ to $17.2 \mathrm{~nm}$ and a full width at half-height $\Delta \mathrm{D}$ in the 5-6 $\mathrm{nm}$ range.
\end{abstract}

Keywords: nanoparticles, mössbauer spectroscopy, magnesioferrite

\section{Introduction}

Nanosized ferrites display physical and chemical properties which may be quite different from those of their bulk counterparts. Magnesioferrite $\left(\mathrm{MgFe}_{2} \mathrm{O}_{4}\right)$ is one of the most interesting, because, due to its small magnetocrystalline anisotropy, superparamagnetic properties are still present at relatively low temperatures and/or high magnetic fields. The purpose of this work was to investigate the influence of annealing on the average particle size and particle size distribution of $\mathrm{MgFe}_{2} \mathrm{O}_{4}$ nanoparticles prepared using the sol-gel/ combustion method ${ }^{1}$, a fast and relatively inexpensive technique. The average particle size was determined by $\mathrm{X}$ ray diffraction, while the particle size distribution was obtained by measuring at several temperatures the relative intensity of the Mössbauer spectra due to superparamagnetic particles and to ferrimagnetic particles, a method that has already been applied successfully ${ }^{2}$ to another nanosized ferrite, $\mathrm{CoFe}_{2} \mathrm{O}_{4}$.

\section{Experimental Procedure}

\subsection{Sample preparation}

Analytical grade $\mathrm{Fe}\left(\mathrm{NO}_{3}\right)_{3} \cdot 9 \mathrm{H}_{2} \mathrm{O}, \mathrm{Mg}\left(\mathrm{NO}_{3}\right)_{2} \cdot 6 \mathrm{H}_{2} \mathrm{O}$, and $\mathrm{C}_{6} \mathrm{H}_{8} \mathrm{O}_{7} \cdot \mathrm{H}_{2} \mathrm{O}$ were dissolved in deionized water to obtain the starting solution. The concentrations of ferric nitrate, magnesium nitrate and citric acid were $0.5,0.25$ and $0.75 \mathrm{M}$. The solution was stirred for 4 hours at $70{ }^{\circ} \mathrm{C}$, heated to $90{ }^{\circ} \mathrm{C}$ and kept at this temperature until the sol turned into a transparent gel. The gel was then heated to $200{ }^{\circ} \mathrm{C}$ for 20 minutes so that auto-combustion would take place. Finally, the product was annealed in a furnace for 2 hours at different temperatures.

\subsection{Measurements}

$\mathrm{X}$ ray diffraction patterns were obtained using an XPert Pro Panalitical diffractometer with $\mathrm{Cu} K \alpha$ radiation $(\lambda=1.5418 \AA)$. The average particle size was calculated from line broadening using the TOPAS application ${ }^{3}$, academic edition.

Mössbauer spectra were recorded at several temperatures between $25 \mathrm{~K}$ and room temperature in a homemade instrument using a source of $57 \mathrm{Co}(\mathrm{Rh})$ with an activity of about $50 \mathrm{mCi}$.

\section{Experimental Results and Analysis}

Table 1 shows the average particle sizes, as calculated from the $\mathrm{X}$ ray spectra shown in Figure 1, for samples as prepared and after annealing at three different temperatures.

The Mössbauer spectra of sample 2 in Table 1 are shown in Figure 2 for several different measurement temperatures. While at room temperature there is a doublet due to superparamagnetic relaxation, at lower temperatures one sees a sextet which is characteristic of bulk magnesioferrite ${ }^{4}$. By taking the ratio of the area under the doublet to the area under the sextet, it is possible to estimate the volume fraction of unblocked particles for each measurement temperature. The 
Table 1. Properties of $\mathrm{MgFe}_{2} \mathrm{O}_{4}$ nanoparticles as prepared and annealed at three different temperatures.

\begin{tabular}{ccccc}
\hline Sample & $T_{\mathrm{a}}\left({ }^{\circ} \mathrm{C}\right)$ & $\langle D\rangle(\mathrm{nm})$ & $D m(\mathrm{~nm})$ & $\Delta D(\mathrm{~nm})$ \\
\hline 1 & as prepared & $8.1 \pm 0.1$ & 6.4 & 5.7 \\
2 & 400 & $13.2 \pm 0.1$ & 11.6 & 5.5 \\
3 & 500 & $13.4 \pm 0.1$ & 12.5 & 5.3 \\
4 & 600 & $17.8 \pm 0.1$ & 17.2 & 6.5 \\
\hline
\end{tabular}

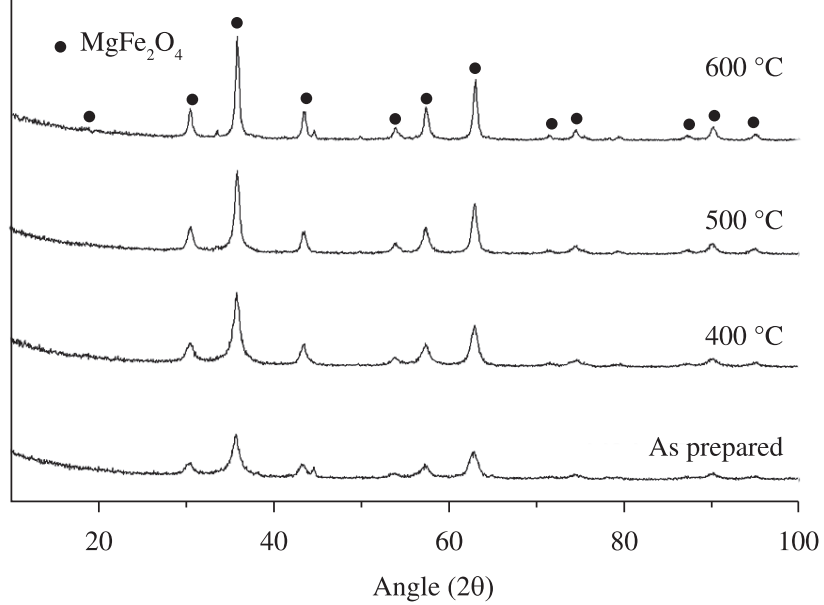

Figure 1. $\mathrm{X}$ ray diffraction patterns of $\mathrm{MgFe}_{2} \mathrm{O}_{4}$ samples as prepared and annealed at different temperatures.

result is shown in Figure 3, where the dots are the experimental points and the line is a fit to a cumulative log-normal function

$$
f(T)=C_{1}+C_{2} \operatorname{erf}\left(\frac{\ln T-\mu}{\delta \sqrt{2}}\right)
$$

where $T$ is the absolute temperature, $\operatorname{erf}(T)$ is the error function, $C_{1}$ and $C_{2}$ are constants and $\mu$ and $\delta$ are adjustable parameters. The best fit was obtained with $C_{1}=0.64, C_{2}=0.61, \mu=5.70$ and $\delta=0.64$.

The distribution of unblocking temperatures of the system is given by ${ }^{5,6}$

$$
P(T)=C\left(\frac{1}{T}\right)^{1 / 3} \frac{d f(T)}{d T}
$$

where $C$ is a normalization constant.

The temperature dependence of Equation 2 may be converted to a dependence on particle diameter (thus yielding the particle size distribution) using the relation ${ }^{5,6}$

$$
D(T)=\langle D\rangle\left(\frac{T}{\left\langle T_{c}\right\rangle}\right)^{1 / 3}
$$

where $D$ is the particle diameter, $\langle D\rangle$ is the average particle diameter, as estimated from the $\mathrm{X}$ ray results, and $\left\langle T_{c}\right\rangle$ is the average blocking temperature, given by

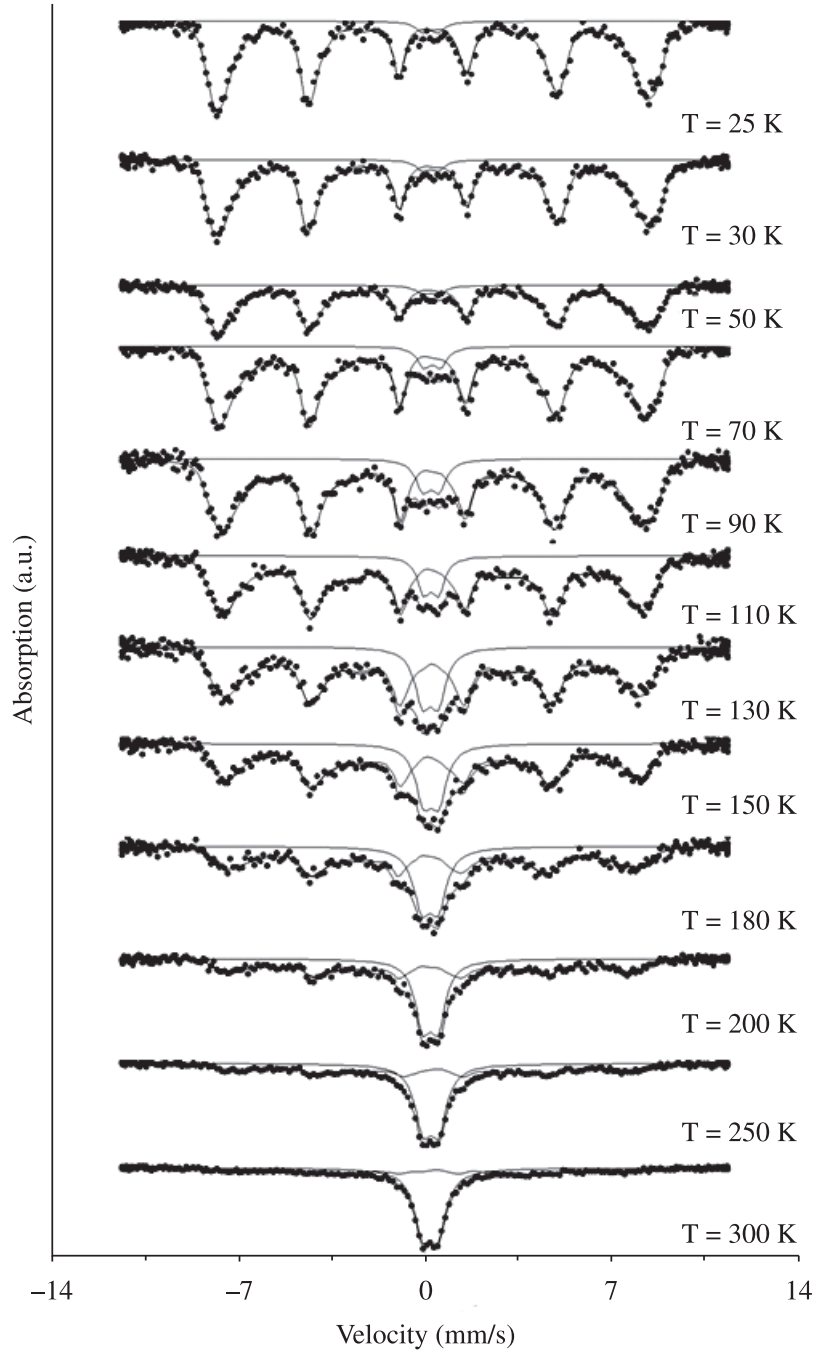

Figure 2. Mössbauer spectra of sample 2 at several temperatures.

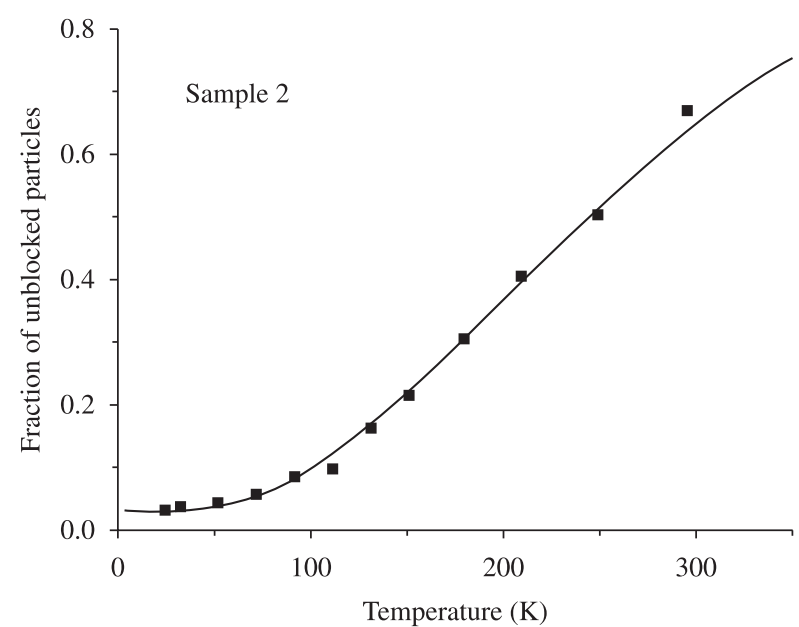

Figure 3. Temperature dependence of the volume fraction of unblocked particles in sample 2 of Table 1 (annealed at $400{ }^{\circ} \mathrm{C}$ ), calculated from the Mössbauer spectra. The dots are experimental points; the line is a fit to a cumulative log-normal function (see text). 


$$
\left\langle T_{c}\right\rangle=\frac{\int_{0}^{\infty} T P(T) d T}{\int_{0}^{\infty} P(T) d T}
$$

The result is shown in Figure 4 (curve 2), which is a log-normal distribution with average diameter $\langle\mathrm{D}\rangle=13.2 \mathrm{~nm}$, most probable diameter $\mathrm{Dm}=11.6 \mathrm{~nm}$ and full width at half maximum $\Delta \mathrm{D}=5.5 \mathrm{~nm}$. Similar results for samples as prepared and annealed at different temperatures are shown in Table 1 and Figure 4.

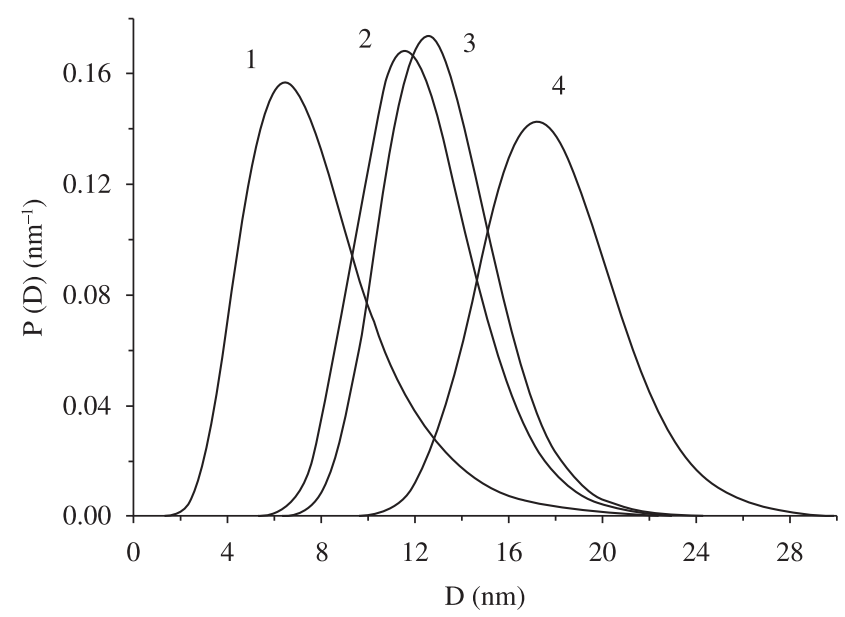

Figure 4. Particle size distributions of $\mathrm{MgFe}_{2} \mathrm{O}_{4}$ samples as prepared and annealed at different temperatures. The numbers refer to the annealing conditions given in Table 1: 1 , as prepared; 2 , annealed at $400{ }^{\circ} \mathrm{C} ; 3$, annealed at $500{ }^{\circ} \mathrm{C}, 4$, annealed at $600{ }^{\circ} \mathrm{C}$.

\section{Conclusions}

The sol-gel/combustion technique has been used to prepare $\mathrm{MgFe}_{2} \mathrm{O}_{4}$ nanoparticles, which were annealed at different temperatures. $\mathrm{X}$ ray diffraction patterns show broad peaks in the positions corresponding to the crystal structure of magnesioferrite. Mössbauer spectra exhibit superparamagnetic behavior, confirming that the particles are in the nanometric range. Analysis of the broadening of the $\mathrm{X}$ ray lines shows that the average particle size increases with increasing annealing temperature. Analysis of the temperature dependence of the Mössbauer spectra of as prepared and annealed samples yields fairly narrow lognormal distributions of particle sizes. The results suggest that the sol-gel/ combustion technique may be used to synthesize nanosized $\mathrm{MgFe}_{2} \mathrm{O}_{4}$ powders whose average size can be controlled by subsequent annealing without appreciably changing the distribution of particle sizes.

\section{References}

1. Huang Y, Tang Y, Wang J, Chen Q. Synthesis of $\mathrm{MgFe}_{2} \mathrm{O}_{4}$ nanocrystallites under mild conditions. Materials Chemistry and Physics. 2006; 97(2-3):394-397.

2. de Biasi RS, Figueiredo ABS, Fernandes AAR, Larica C. Synthesis of cobalt ferrite nanoparticles using combustion waves. Solid State Communications. 2007; 144(1):15-17.

3. Bruker AXS. DIFFRACplus TOPAS. Available from: <http://www.brukeraxs.de/topas.html >. Access in: 02/04/2009.

4. Chen Q, Rondinone AJ, Chakoumakos BC, Zhang ZJ. Synthesis of superparamagnetic $\mathrm{MgFe}_{2} \mathrm{O}_{4}$ nanoparticles by coprecipitation. Journal of Magnetism and Magnetic Materials. 1999; 194(1-3):1-7.

5. de Biasi RS, Folly WSD. Use of ferromagnetic resonance to determine the size distribution of magnetic particles. Physica B. 2002; 321(1-4):117-119.

6. de Biasi RS, Gondim EC. Use of ferromagnetic resonance to determine the size distribution of gamma- $\mathrm{Fe}_{2} \mathrm{O}_{3}$ nanoparticles. Solid State Communications. 2006; 138(6):271-274. 
